\title{
SCIENCE AND THE WORLD MIND
}

$\mathrm{A}^{1}$ LTHOUGH no thorough analysis of the concept of world mind was attempted at the Conference on Science and World Order, certain aspects of human consciousness were emphasized and many interesting avenues for further investigation were opened.

Mr. H. G. Wells issued the challenging statement that there is no orderly world mind as yet but only a world dementia, a gabble of unheeded and inconsecutive utterances, and that it is the business of scientific men to prepare a working conception of organized will and knowledge upon which mankind can go.

For man as a social being, the essential thing is that he stands at the growing point of a vast evolutionary process the characteristics of which we can see pretty well, according to Dr. J. Needham of the University of Cambridge. The march of living organization, the progress of the world mind, will not stand still where it is to-day. For us, at the middle point of time, the first duty is to appraise the social forces at work around us, to see in what direction they are leading: Which of them make for higher social organization, greater human unity, community and solidarity? This is the point from which we should approach traditional systems of morality.

Science is man's consciousness, his collective property of knowledge about the world in which he lives, according to Prof. Max Born, of the University of Edinburgh. For practical purposes we all agree about the direction which we wish it to take: peaceful co-operation, a maximum of freedom for the individual combined with the optimum of organized efficiency in production, economic and political security as formulated in the Atlantic Charter.

Mr. Wells stressed the fact that conditions of human life have changed so fundamentally during the last forty years that Homo sapiens cannot go on living as he has been doing during the past few score thousands of years. If he fails to adapt himself to the new conditions he will degenerate or perish altogether.

Aviation, radio and other means of communication have abolished distance. A stupendous increase in the power of realizing and utilizing material energy has reduced the need for unskilled labour and has led to technological unemployment.

States and communities to-day are biologically different organisms from what they were a few hundred years ago. The average age and literacy are greater ; new factors-advertising and propaganda, mass production and selling-have crept in .
If there is to be peace on earth henceforth, there must be a federal control of the air and of the material of international transport; of the conservation of world resources, and a declaration of human rights that will ensure for everyone a fair participation in the world's resources and a responsible ownership in our planet.

Immediate steps should be taken towards the development of a world mind : a world language with suitable spelling and phonetics and words that do not change their meaning according to circumstances and are not easily misunderstood. Finally a world-wide memory-a world encyclopædia-or better a world institute of thought and knowledge.

On the question of a world language, Mr. Wells, while highly critical of English as it now stands, considers that some slightly modified form of Basic English, with simplified spelling, might well form the basis for an international language. Prof. L. Hogben, who stated that four hundred international universal languages have been put forward since the seventeenth century, considers that Basic English possesses many of the necessary qualifications for an international language; but he is doubtful about using any of the current languages as a basis because of the prejudices associated with them.

In the matter of spelling Mr. Wells quoted Mr. G. B. Shaw as saying that about forty-one characters are needed to cover world needs.

The institute of thought and knowledge, the world-wide memory organization for the world mind, must have ready access to all the world's learning and thinking. It would include all the museums, galleries, libraries, atlases, surveys and muniment rooms in the world. Much has been done in the matter of documentation to bring together materials from a great number of countries, and the method of microphotography developed by Dr. Kenneth Mees and Mr. Watson Davis of Science Service, Washington, enables the contents of a whole library to be condensed in a small box. In addition we need for the workroom of the world mind general and particular digests, prepared by hundreds of thousands of workers continually bringing up to date and replanning the general and particular summaries.

Mr. Wells sees in the British Association, and particularly in the Division for the Social and International Relations of Science, and in kindred associations throughout the world, the making of a great international organism for pooling the scatterbrain world into a sane effective mentality. 
Through the British Association the specialist can teach and learn and yet remain human.

A proper development of the world mind can only be achieved by a correct education of the young and the re-education of the adult mind to appreciate the full significance of the developments of science. In addition, as Prof. Born pointed out, if science is to be taught in a way appropriate to its place in the world order there must exist a clear idea of the order. This is a question of economics and politics guided by principles of philosophy and religion. The two extreme and opposing theories of dialectical materialism and individualistic idealism need not be irreconcilable any more than the two theories of light, the corpuscular and wave theories, to which Bohr's principle has supplied a solution, namely that waves and particles are limiting cases suitable for the description of particular aspects of the phenomena, two different languages telling the same tale, not contradictory but complementary. We cannot eliminate from human affairs either the collective or the individualistic aspects any more than we can deal with radiation without using notions both of particles and waves. We have to reconcile the individualist with planning, which is unavoidable, and the socialist with freedom of research, which is imperative.

Dealing with the curriculum of schools, Mr. J. A. Lauwerys, of the University of London Institute of Education, stated that much of it has been inherited from a pre-scientific age and that great changes are urgently needed. We must make sure that the material presented during the lessons is relevant to the needs and the conditions of twentieth-century industrial society. A curriculum planned around natural science and social studies is required. To this end a study of the history of science and technology, such as the eight million dollar research into curriculum needs, carried out over the last ten years in the United States, is enormously valuable. Science will cease then to be a specialized study and will help to explain social organization and get people used to thinking in terms of human welfare.

Mr. J. G. Crowther, of the British Council, dealt with the education of the adult mind. In his view contemporary automatism-repetition of the same errors by nations with different forms of governments-is due to a lack of adaptation of social forms to the possibilities of technique and can only be remedied by the scientific education of the general public.

Dr. Julian Huxley, in a paper circulated under the title of "Scientific View of Education as a Social Function", likewise advocates a proper education of the parents as a prime essential. $\mathrm{He}$ considers this necessary in order that they should not encourage and intensify the normal infantile repressions in the child. The persistence of such repressions into adult life has several disadvantages, notably the immobilizing of a considerable amount of so-called mental energy, deadlocked between the repressing and the repressed impulses.

Thus, in one sense, the most important single task of education is not an intellectual, but a moral and emotional one, the substitution of conscious, in place of unconscious, repression in the light of tolerance and reason.

The education of the emotional aspect of personality was even more strongly emphasized by Mrs. S. Neville-Rolfe. Every educational system, she stated, has concentrated on the training of intelligence, none has yet taken cognizance of the paramount influence of the emotional condition of man or his behaviour, or attempted to apply even our present knowledge of psychology, etc. (see p. 425). A true democracy can only be created by those who are emotionally and intellectually developed, inspired with a positive purpose in life. The emotionally immature belonging to a previous generation, are not qualified to govern or to lead youth in the present world crisis. The young to-day have a deep sense of spiritual values. They can appreciate the opportunity and accept the responsibility of mastering the forces of evolution and direct them to the development of man.

The Conference scarcely touched upon the problem of how to obtain agreement and unity of action among scientific workers, a point raised by Mr. Wells in his opening remarks. All those who have followed the deliberations of groups of highly intelligent men and women, from the League of Nations Committee for International Intellectual Co-operation onwards, cannot have failed to appreciate the difficulty of obtaining a result commensurate with the great abilities of those represented on such committees.

It seems well worth while investigating how to bring about the necessary unity of feeling, and to arouse sufficient enthusiasm among people agreed intellectually upon the work to be done in order to enable them to pull together as a team. Co-opting more of the younger men in the counsels of science will undoubtedly help much towards this badly needed unity. At present some of the more progressive men of science feel keenly the neglect of their services, especially when older authorities are complaining of having too much to do, too many committees to attend, etc. Once this feeling almost of frustration is eliminated, and younger men are given their rightful place in the advancement of science, a closer unity of feeling will be established. 